\title{
BMJ Open A pilot study of a neuroscience-based, harm minimisation programme in schools and youth centres in Australia
}

\author{
Jennifer Debenham (D , ${ }^{1}$ Louise Birrell, ${ }^{1}$ Katrina Champion (D) , ${ }^{1}$ Mina Askovic, ${ }^{2}$ \\ Nicola Newton ${ }^{1}$
}

To cite: Debenham J, Birrell L, Champion $\mathrm{K}$, et al. A pilot study of a neuroscience-based, harm minimisation programme in schools and youth centres in Australia. BMJ Open 2020;10:e033337. doi:10.1136/ bmjopen-2019-033337

- Prepublication history and additional material for this paper are available online. To view these files, please visit the journal online (http://dx.doi. org/10.1136/bmjopen-2019033337).

Received 01 August 2019 Revised 14 November 2019 Accepted 07 January 2020

\section{Check for updates}

(C) Author(s) (or their employer(s)) 2020. Re-use permitted under CC BY-NC. No commercial re-use. See rights and permissions. Published by BMJ.

${ }^{1}$ Faculty of Medicine and Health, The University of Sydney, Sydney, New South Wales, Australia

${ }^{2}$ Business Faculty, The University of Sydney, Sydney, New South Wales, Australia

\section{Correspondence to} Ms Jennifer Debenham; jennifer.debenham@sydney. edu.au

\section{ABSTRACT}

Objectives The primary aim is to evaluate the feasibility of a newly developed, neuroscience-based, alcohol and other drug (AOD) use prevention programme, 'The Illicit Project', in Australian older adolescents. The secondary aim is to investigate the impact of the programme on students' drug literacy levels (a combination of knowledge, attitudes and skills).

Design A pilot study examining the feasibility of The Illicit Project in Australian schools was conducted.

Participants Students aged 15-19years from two secondary schools and a youth centre and 11 teachers and health professionals from various organisations in Sydney were recruited.

Intervention The intervention consisted of three $90 \mathrm{~min}$ workshops delivered by trained facilitators within a month. Primary and secondary measures Students completed a drug literacy questionnaire before and after intervention. All participants (students, teachers and health professionals) completed an evaluation questionnaire postprogramme delivery. A paired-sample t-test and descriptive analytics were performed.

Results Students $(n=169)$ demonstrated a significant increase in drug literacy levels from preintervention to postintervention $(t(169)=-13.22, p<0.0001)$. Of students evaluating the programme $(n=252)$, over threequarters agreed that The Illicit Project was good or very good (76\%), that the neuroscience content was interesting $(76 \%)$ and relevant $(81 \%)$, and that they plan to apply the concepts learnt to their own lives (80\%). In addition, all teachers and health professionals $(n=11)$ agreed that the programme was feasible and valid for schools and perceived the programme to be effective in reducing the harms and use of AOD.

Conclusions There is evidence to suggest that The Illicit Project is credible and feasible in the school environment and there are preliminary data to suggest it may help to improve drug literacy levels in young people. A large-scale evaluation trial of the intervention will be conducted to determine the programme's effectiveness in minimising the harms of AOD in older adolescents.

\section{BACKGROUND}

Adolescence is characterised by an increase in risky behaviours including alcohol and other drug (AOD) use which carries significant physical and psychological health burden. ${ }^{12}$

\section{Strengths and limitations of this study}

- A pilot study examining the feasibility of the neuroscience-based alcohol and other drug prevention programme 'The Illicit Project' in Australian schools, with 272 students and 11 teachers and health professionals.

- Student evaluations were overwhelmingly positive with over $80 \%$ confirming the information was relevant and that they plan on using it in their own lives.

- Teacher and health professional evaluations were extremely positive with all teachers confirming the programme is acceptable and feasible within the school system and $89 \%$ stating it was better or much better than other programme.

- Overall, the programme appears both feasible and credible to students, teachers and health professionals in Sydney.

- A large-scale trial of the programme will be conducted to determine the effectiveness of the programme in Australia.

Globally, there has been a significant downward trend in binge drinking and the risky use of illicit substances other than cannabis, with prevalence rates for junior high school students (age 12-15 years) being particularly low. ${ }^{34}$ Similarly, in Australia, there has been a noteworthy delay in the age of first time AOD use, with young people generally waiting until the senior years of high school being aged on average 16.1 years and 19.7 years, to engage in alcohol and drug use, respectively. ${ }^{5}$ Despite this positive shift away from early-onset AOD use, young people engaging in risky use is increasing and the health burden for young people continues to climb. ${ }^{16}$ Pointedly, AOD prevention programme tends to target junior high school students and generally discontinues for senior students (16-19 years)despite this age group representing the new age of initial AOD exposure. ${ }^{7-9}$ Moreover, the effectiveness of the established prevention programme is small to modest, ${ }^{810}$ with the effect size of most programme rapidly 
diminishing by late secondary school ${ }^{11}$ and very few showing long lasting behavioural effects. ${ }^{1213}$ To compound this, the Australian school curriculum mandates for AOD education during the junior years of school; however, it does not account for senior students, meaning many older adolescents receive no AOD education past the age of 16 years (grade 10). ${ }^{14}$ To leverage the final opportunity to universally reach young people in the school environment, supplementary prevention programme that targets older adolescents in the senior years of school would be beneficial.

Prevention science is predicated on an undefined mixture of active ingredients that enable success. ${ }^{15}$ For a heterogeneous cohort of low-risk and high-risk young people, the implementation factors that influence programme impact include first, the credibility of the message. Science-backed, non-judgemental messages that offer a balanced argument are effective in minimising AOD-related harm. ${ }^{16-18}$ Information that contradicts lived experience is not deemed credible ${ }^{19}$ and often approaches focusing on social influence, and resistance training tends to have a smaller impact on students who have already initiated AOD use. ${ }^{20-23}$ Second, the relevance of the information is a key predictor of programme success; displaying the serious, distal harms of AOD often does not result in decreased use, ${ }^{24}$ and images that are too confronting or disturbing are more easily ignored by young people. ${ }^{25}$ Moreover, tailoring programme to meet the precise concerns of specific groups can foster participant buy-in and be conducive to better health outcomes. ${ }^{26}$ Additionally, for young people, the perception of peer substance use is a key predictor of personal use and contributes to the development of normative expectations. Hereby correcting misinformation is highly impactful in AOD education. ${ }^{16}{ }^{27}$ What is more student engagement can be improved through the addition of interactive programme components. ${ }^{28}{ }^{29}$ Lastly, the memorability of the style of delivery can predict ongoing success; exclusively knowledge-based content does not assure behaviour change. ${ }^{20}$ A programme that leverages digital technology not only boost students' recall of material but also further able to increase implementation fidelity. ${ }^{27}$ With these enabling factors in mind, it is time to explore new avenues to deliver harm-minimisation information to young people and increase the long-term impact of AOD prevention.

There is compelling evidence to suggest that neuroscience education may be effective in conveying complex health-related information to young people. ${ }^{30} 31$ Young people are more likely to overweigh the importance of health messages when they are accompanied by neuroscience content, such as descriptions and images of the brain; this effect has been coined 'the seductive allure of neuroscience explanations' $\left(\mathrm{SANE}^{32}{ }^{33}\right)$. Young people rate three-dimensional brain graphics as more credible than two-dimensional brain graphics and text, which reflects the authority real-life visuals command in the perceived truth of health messages. ${ }^{34}{ }^{35}$ Young people's interest in the brain and the inherent relatability of neuroscience may also create a non-judgemental context to engage a wide audience in an otherwise stigmatising field. ${ }^{36-38}$ Neuroscience is arguably central in understanding the short-term and long-term impacts of AOD and promotes awareness of the progression of harm occurring when use transitions from single-time or 'recreational' use to habitual use. ${ }^{39}$ In addition, neuroscience education may offer insight into executive functioning and help to improve self-regulation in young people, ${ }^{37} 38$ all of which mediate against substance misuse. ${ }^{40}$ Although the SANE effect has not been widely tested in this context, ${ }^{41}$ it may provide a credible, relevant and memorable context to upskill young people in AOD harm minimisation.

A neuroscience-based, harm-minimisation programme that targets older adolescents, known as The Illicit Project, was designed to address these gaps. The primary aim of this study is to evaluate The Illicit Project in terms of (1) credibility, memorability and relevance for young people; (2) feasibility in schools; and (3) acceptability to teachers and health professionals. The secondary aim was to investigate preliminary effects of the programme on students' drug literacy levels, which we conceptualise as a combination of knowledge, attitudes and skills required to minimise the harms of AOD (see figure 1).

\section{METHOD}

\section{Participant characteristics and sample size considerations}

In order to assess the feasibility of the programme in both structured (eg, classroom) and unstructured (eg, youth centre) environments, we aimed to recruit participants from at least one school and one youth centre. We also aimed to include participants from at least one independent (private) and one public high school to assess the feasibility of the programme in both school settings. ${ }^{42}$ To maintain consistency with the size of other pilots in the area ${ }^{43}$ the sample includes one representative cluster from a private school, a public school and a youth centre, and the associated teachers and health professionals.

\section{Recruitment of participants}

Organisations in Metropolitan Sydney were recruited via the Positive Choices online community newsletter, the monthly State School Link newsletter and through contacts at a Sydney Community Drug Action Team (CDAT). Initial contact with the schools and youth centres was made via phone calls followed by an email invitation. After an expression of interest was received, meetings were held between the researchers and the principal or staff members at the relevant organisations to explain the study. Two secondary schools, one youth centre and a local CDAT, agreed to participate.

\section{Consent}

Opt-out information and consent forms were sent home to parents or guardians of all students (15-19years old) at the participating schools and sites. Only students 
who received parental consent and who provided active written consent themselves were eligible to participate. All teachers and health professionals provided active written consent before participation in the study. It was made clear that participants could withdraw at any stage from the study without consequence. As the programme aligns with the New South Wales (NSW) Crossroads Curriculum and is considered a normal part of schooling, students who did not receive parental consent to participate in the research study were still able to participate in the programme but did not complete questionnaires.

\section{Procedure}

At preintervention and immediately postintervention, students completed a confidential drug literacy (knowledge and skills) questionnaire in a supervised setting using paper and pencil, which lasted approximately 5 min. Due to the low sensitivity of the items, students included their names on the questionnaire at baseline and post-test to enable their responses to be easily matched. Immediately postintervention, students also completed an anonymous evaluation of the intervention lasting approximately $5 \mathrm{~min}$. Teachers and health professionals, who were present for at least two-thirds of the programme, were invited to complete an anonymous evaluation questionnaire postintervention that lasted $30 \mathrm{~min}$ and they were reimbursed $\$ 50$ for their time. All data are stored deidentified.

\section{Intervention programme}

The Illicit Project is a neuroscience-based, harmminimisation programme that aims to deliver practical and relevant education to young people to reduce the risky use of AOD. The Illicit Project is a universal programme; however, to appeal to an older audience where exposure to AOD use is more common, it incorporates strategies commonly used in targeted prevention programme, such as psychosocial approaches and behaviour change tools. The programme is comprised of three $90 \mathrm{~min}$, multimodal workshops with interactive, challenge-based activities that

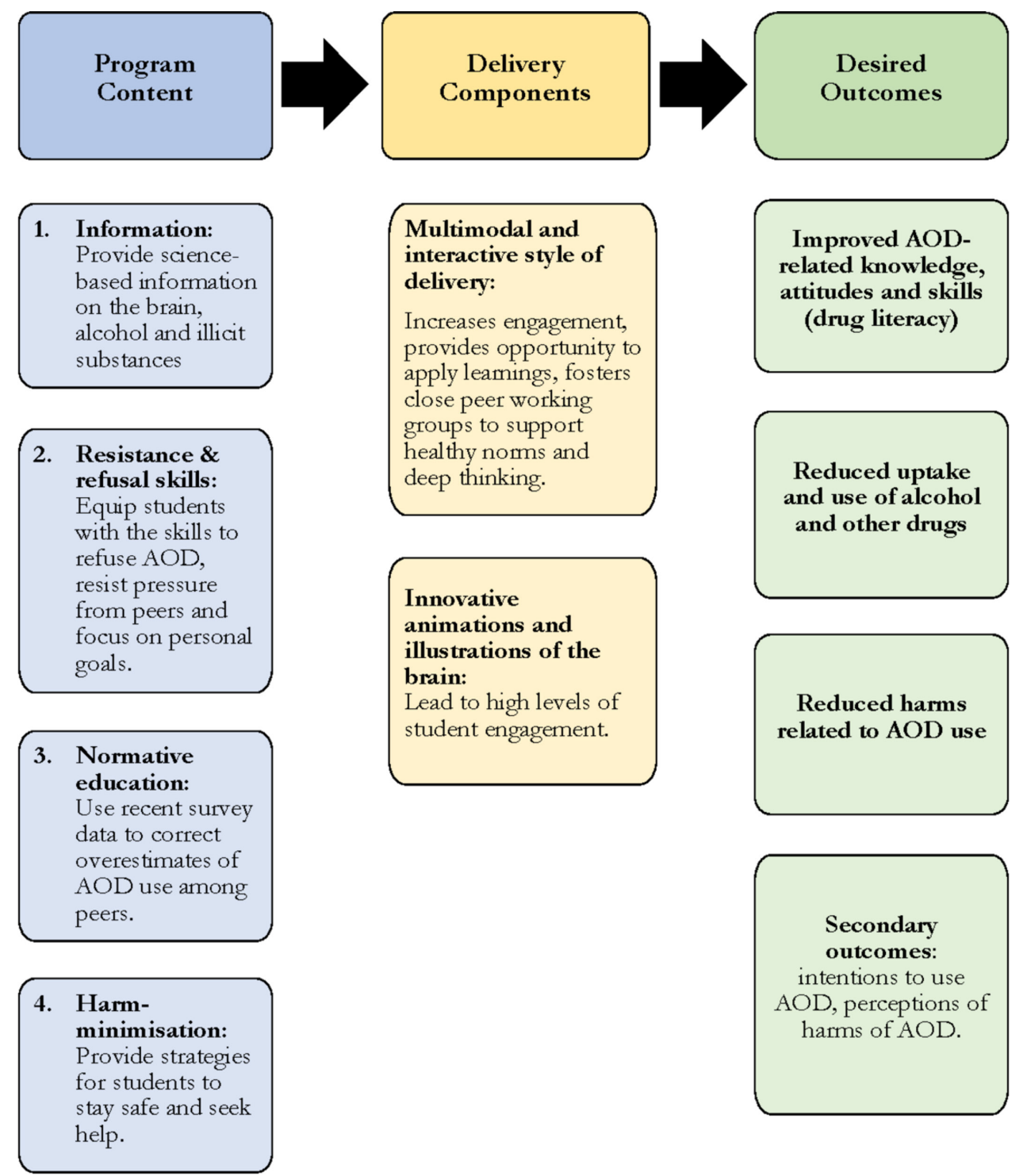

Figure 1 The Illicit Project logic model. AOD, alcohol and other drug. 
was devised to upskill young people in drug literacies. In workshop one of the programme, students learn about key neuroscience principles, the architecture of the growing brain and the prevalence of alcohol in Australian society. In workshop two, students examine the effects of drugs such as methylenedioxymethamphetamine or ecstasy and cannabis on the brain over the short-term and long-term and devise harm reduction tools and strategies relevant to their own life. Workshop three is centred around the science of habit and addictive behaviours and students discuss and share strategies around mental health and wellness. Online supplementary appendix 1 outlines the specific content covered in each of the three The Illicit Project workshops.

In this pilot, the workshops were delivered within a 1-month timeframe to reduce attrition within the small sample, while allowing participants the time to reflect and recap on previous learnings. The workshops are delivered by trained, university graduates from science and health disciplines, and depending on the size of the participant group, the number of facilitators varies to facilitate smaller group work. In the current pilot, the workshop sizes ranged from 10 to 200 participants and were delivered in a classroom, a youth centre room and an auditorium. The programme is aligned with the NSW Stage 6 Crossroads Curriculum under the optional focus area 'Alcohol and Drugs'.

\section{Measures}

\section{Student evaluation}

Based on a previously delivered evaluation measure in this area, ${ }^{44}$ students evaluated the programme by indicating on a five-point Likert scale how strongly they agreed or disagreed with seven statements relating to content and how believable, relevant and memorable they found the programme and its messages to be. Statements included "I plan to use the information I learnt in this program in my own life" and "The neuroscience content was interesting to me". There were three open-ended questions where students described their most and least favourite parts of the programme and provided comments for improvement. The student evaluation scale demonstrated respectable reliability $(\alpha=0.87)$.

\section{Teacher and health professional evaluation}

Teachers and health professionals evaluated the programme by answering a 13-item multiple choice questionnaire, adapted from previous programme evaluation studies, ${ }^{43}$ with the option to provide an extended response on questions relating to programme content, feasibility, perceived effectiveness and overall ratings of the programme.

\section{Drug literacy assessment}

Adapted from previously used AOD knowledge and skill questionnaires, ${ }^{43}$ a 20 -item tool including both knowledge, attitudes, intentions and skills was custom built to assess drug literacy levels in study participants. The
'Drug Literacy Questionnaire' was chosen over actual behaviours due to the short time between the pretrial and post-trial evaluations. The drug literacy questionnaire demonstrated acceptable reliability $(\alpha=0.67)$. The drug literacy questionnaire includes items relating to students; (1) knowledge (eg, "Cannabis is an addictive substance"), (2) attitudes (eg, "I feel confident that I could minimise the short-term harms associated with drugs"), (3) intentions to use (eg, "I feel inclined to take drugs") and (4) skills (eg, "I know where to go for help if I needed it"). Responses to the 14 knowledge questions were scored and coded as correct or incorrect and responses to the six attitude or intention or skill items were coded on a five-point Likert scale ranging from 0 (strongly disagree) to 4 (strongly agree). All items were summed to give an overall drug literacy score (total score ranging from 0 to 38 ), with higher scores indicating greater drug literacy (online supplementary appendix 1).

\section{Patient and public involvement}

The resources in the programme were specifically designed to meet the needs and experiences of young people (15-19years) and the measures used in the surveys are all age-appropriate. A summary of the results will be provided to the key contact at participating school to forward to students, teachers and health professionals. Members of the public were not involved in the design or reporting of this research.

\section{RESULTS}

\section{Analyses}

Two paired-sample t-tests were conducted using the Statistical Package for Social Sciences (SPSS V.21.0). Only participants who completed both the preintervention and the postintervention questionnaires and could be matched were included in the drug literacy rating. To qualify as complete, students had to answer at least 10 of the 14 knowledge items and they were given an individual mean score for the incomplete questions.

\section{Sample characteristics}

Of the 272 students (aged 15-19 years) who provided consent and completed the baseline questionnaire, 252 completed the post-program questionnaire and evaluation and 169 completed both the baseline and postintervention questionnaire and were able to be matched. There were 11 teachers and health professionals who evaluated the programme with an average of 7 years in the field (mean age $=32.8$ years; $\mathrm{SD}=12.2 ; 73 \%$ women) .

\section{Student evaluation}

Over three-quarters of students $(76 \%)$ rated the overall programme as good or very good, $81 \%$ agreed (strongly or moderately) that the activities and discussions were relevant to their lives and the lives of their friends, $80 \%$ agreed (strongly or moderately) that they plan to use the information they learnt in their own lives, $80 \%$ agreed 
Table 1 Student evaluation of the Illicit Project $(n=252)$

\begin{tabular}{|c|c|c|c|c|c|}
\hline & $\begin{array}{l}\text { Strongly } \\
\text { agree }\end{array}$ & $\begin{array}{l}\text { Moderately } \\
\text { agree }\end{array}$ & Undecided & $\begin{array}{l}\text { Moderately } \\
\text { disagree }\end{array}$ & $\begin{array}{l}\text { Strongly } \\
\text { disagree }\end{array}$ \\
\hline The style of delivery was engaging (\%) & 21.0 & 48.0 & 16.3 & 13.1 & 1.6 \\
\hline The neuroscience content was interesting (\%) & 28.2 & 48.0 & 16.7 & 6.0 & 1.2 \\
\hline The neuroscience content was easy to follow (\%) & 34.5 & 45.6 & 15.5 & 4.0 & 0.4 \\
\hline $\begin{array}{l}\text { The activities and discussions were relevant to current or } \\
\text { future experiences in my life or lives of my peers (\%) }\end{array}$ & 39.3 & 41.7 & 12.7 & 6.3 & 0 \\
\hline I would like to learn other PDHPE topics in this way (\%) & 25.4 & 34.1 & 25.4 & 10.7 & 4.4 \\
\hline $\begin{array}{l}\text { I plan to use the information I learnt in this programme in my } \\
\text { own life (\%) }\end{array}$ & 40.9 & 38.9 & 15.1 & 4.4 & 0.8 \\
\hline
\end{tabular}

PDHPE, Personal Development, Health and Physical Education.

(moderately or strongly) that the neuroscience was easy to follow, $76 \%$ agreed (strongly or moderately) that the neuroscience content was interesting, $69 \%$ of students agreed (strongly or moderately) that the programme was engaging, $60 \%$ agreed (strongly or moderately) they wanted to learn other Personal Development, Health and Physical Education (PDHPE) topics in this way (table 1). Further open-ended feedback was collected from students, and the key themes (whereby at least $10 \%$ of students mentioned) are presented in table 2.

\section{Teacher and health professional evaluation}

The majority $(91 \%)$ of teachers and health professionals rated the programme as good or very good, $89 \%$ said it was better (or much better) than other programme, 82\% said they were likely to use The Illicit Project in the future and all but one agreed they would recommend the programme to other people. The large majority of teachers agreed that it would work very well (or extremely well) in the stage 5 PDHP Curriculum, the stage 6 Crossroads Curriculum and in drop-in youth centre environments $(89 \%, 75 \%$ and $100 \%$, respectively). When asked to evaluate the programme's activities, lessons, discussions and style of delivery, all teachers and health professionals $(100 \%)$ reported that it was believable for students aged 15-19years that they would find the harmminimisation approach acceptable, that the educational content is appropriate and that students would be able to understand and remember the concepts being thought.
All teachers and health professionals (100\%) agreed the programme would be effective (somewhat, very or extremely) in minimising the risks associated with AODs and in getting students to adopt strategies that help reduce harm in their life. All teachers and health professionals $(100 \%)$ perceive the programme to be effective in getting students who use AODs, to reduce the risks associated with their use. Avoiding repetition, the key feedback points from teachers and health professionals are illustrated in table 3 .

\section{Student drug literacy levels}

At baseline, the mean drug literacy score was $66 \%$ $(25.1 / 38 ; \mathrm{SD}=4.7)$ and at postintervention, this increased to $79 \%(30.2 / 38 ; \mathrm{SD}=4.8)$, representing a total $13 \%$ increase $(\mathrm{t}(169)=-13.22, \mathrm{p}<0.0005)$ (see figure 2). At baseline, the lowest scoring drug literacy (knowledge) questions (where $>50 \%$ participants scored zero) were questions around normative expectations (Q1 and Q2), alcohol harms (Q4-Q6 and Q10), cannabis (Q9) and the law (Q11). Similarly, the lowest scoring drug literacy (skills) questions (where $>25 \%$ of participants were neutral or disagreed) were around having conversations with parents (QA), minimising the short-term and longterm harms (QD and $\mathrm{QE}$ ) and not feeling inclined to take drugs $(\mathrm{QF})$. The post-test results showed a significant improvement in drug literacy (knowledge), whereby the majority of participants $(>50 \%)$ answered all questions correctly and the large majority of participants $(>75 \%)$

Table 2 Student feedback on the programme

\section{Favourite parts of the programme}

"I really enjoyed seeing the effects of drugs on the brain"

- "Breaking into groups with the researchers and discussing work"

- "Learning about the science of everyday life"

- "Hearing the thoughts of all my peers"

- "Friendly and engaging presenters, [as it] didn't feel like people were being judgmental".

\section{Least favourite parts of the programme}

"The parts on less relevant drugs at this point for me for example, opioids, MDMA"

- "When you presented too much info - use videos"

- "Having to sit still for so long"

- "The parts most people already knew"

- "When it was repetitive"

- "It would have been better if the program was over a whole day not 3 separate days"

MDMA, methylenedioxymethamphetamine. 
Table 3 Teacher and health professional feedback on the programme

\section{Validity and credibility}

- "Because the prevention style was relaxed and information quite conversational, it fitted well in a youth centre setting"

- "The interactive content and trick questions got them thinking"

- "Neuroscience statistics and facts reinforced the content and made it more believable"

- "The animal studies were very effective, good insight"

- "The real-life stories of young people were impactful on students"

- "People engaged well with the content around developing a risk profile and considering all harms, it's a useful message that no drug is ever 'safe' and it all depends on how we measure "danger"'

Teacher feedback for future implementation

- "The PDHPE teachers could take this info and implement it in a way that fits in sensitively with the ethos of the school"

- "Include more neuroscience and information about the brain and alcohol's effect on the brain"

- "More tips on harm minimisation and what they can do with themselves and friends when using"

- "Ideally, workshops would be delivered relatively close to each other so you can recap on previous sessions"

PDHPE, Personal Development, Health and Physical Education.

answered 11 out of 14 questions correctly. The three lowest scoring questions whereby a quarter $(<25 \%$ participants) scored zero were around normative expectations (Q1 and Q2) and overall drug harms (Q7) (see online supplementary appendix 2 and 3 ).

\section{DISCUSSION}

The lack of validated, age-appropriate AOD prevention programme for older adolescents is leaving a cohort of young people unsupported when making increasingly complex life decisions. ${ }^{45} 46$ In older adolescence and young adulthood, the high prevalence of risky AOD use and lack of knowledgeor skills around minimising the harm of use indicate that current education received up until grade 10 is inadequate. ${ }^{147}$ This study aimed to evaluate the credibility and feasibility of a newly developed, AOD harm-minimisation programme and its impact

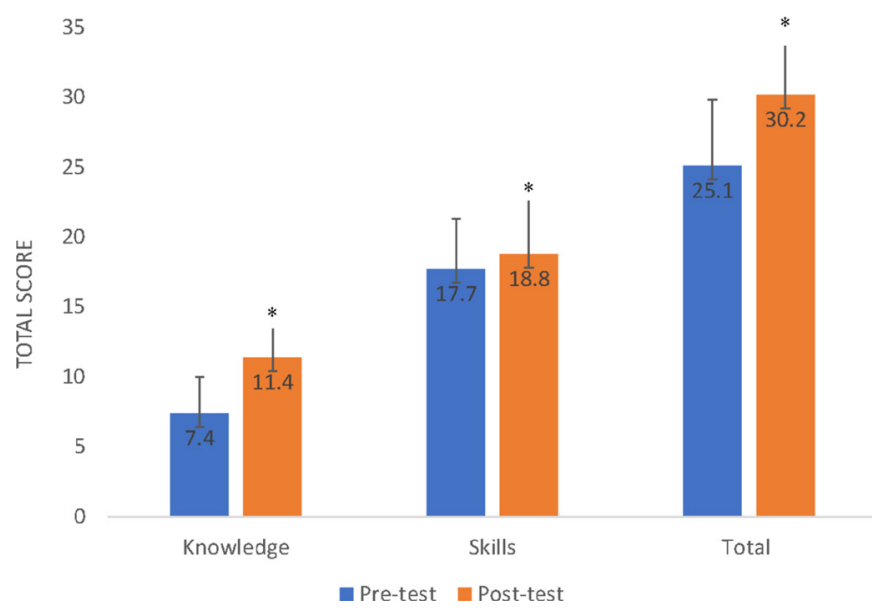

Figure 2 Drug literacy levels at pretest and post-test. on older adolescent's drug literacy (knowledge, attitudes and skills) levels. The baseline results in this study showed the average student had very poor drug literacy (knowledge) levels $(50.7 \%$ scored $50 \%$ or less, $\mathrm{n}=272$ ). Questions surrounding legality, alcohol, illicit drugs, prevalence of peer use and others were the most likely to be answered incorrectly, confirming a significant knowledge gap. Students' low confidence in minimising the short-term and long-term harms of AOD (QD and QE) and broaching AOD-related concerns with their parents (QA) indicate a skill deficiency in older adolescence. This study aimed to evaluate the feasibility and credibility of a newly developed harm-minimisation programme, The Illicit Project, in secondary schools and youth centres across metropolitan Sydney. Furthermore, it aimed to gather preliminary data of the programme's impact on students' drug literacy levels to inform a large-scale trial. Overall, the programme was extremely well received among students, teachers and health professionals, who all agreed it was not only feasible in schools but also the programme would be relevant, credible and memorable in catering to the needs of older adolescents. These results provide preliminary support for the programme's positive influence on drug literacy in young people.

\section{Does the programme resonate with young people?}

The current findings add to the growing SANE literature whereby neuroscience acts as an interesting, engaging and easy to follow medium for young people and extends the use of brain-based images to increase knowledge and skills around AOD harm-minimisation. A large majority of students found learning about the strengths and vulnerabilities of the growing adolescent brain pertinent to their life, the lives of their peers and they planned on using 
this content in the future. This suggests that students are interested in neuroscience and the effects of drugs on the brain. Often in universal AOD education, there remains a subgroup of disengaged students, immune from programme effects ${ }^{48}$; however, this pilot study demonstrates that neuroscience explanations can provide an inclusive medium to engage all students regardless of AOD risk level. Further exemplified by several students' comments, stating that their favourite part of the programme was how 'TIP made [the link between mental health and substance use] scientific, because it removed the stigma from drug use'. Hereby, reducing AOD stigma through neuroscience could provide a viable avenue to promote early help seeking in young people. ${ }^{49}$ The current study adds to the literature by demonstrating that neuroscience education can circumvent otherwise stigmatising messages, by providing simple and concrete explanations that serve to equalise and unite young people from multiple risk backgrounds. ${ }^{49-52}$ Interactive neuroscience education has been shown to improve high-risk students' knowledge and attitudes towards crystal methamphetamine. ${ }^{53}$ This suggests that neuroscience is not only interesting, but it also teaches relevant drug literacies such as, the way drugs interact with one another, which is critical to harm minimisation. ${ }^{16}$ What is more, over the long term, neuroscience may foster better self-awareness and help young people understand their unique predispositions, which precipitates ideas of selfcompassion and mindfulness, ${ }^{545}$ which are integral steps in AOD recovery and may even build credit for different life skills training. ${ }^{5657}$

\section{Does the programme align with education priorities?}

There were extremely positive responses from teachers and health professionals, who all confirmed that the harm-minimisation programme was credible, appropriate for use in the school environment and that they would use the programme again. The large majority of teachers and health professionals attested to the programme's perceived efficacy in curbing the harms associated with AOD use and also perceived TIP to be able to reduce the use of AODs in students who have already initiated use. The perceived efficacy in both reducing the demand for, and the harmful use of, AODs, makes this programme well placed to be implemented in the Australian context. Moreover, it appears that within the Australian context, there is a strong feasibility case for the implementation of programme in grade 10, due to gaps in the curricula for students transitioning into grade 11. Further research with larger sample size would help to determine to what capacity grade 12 students can be engaged in external programme.

\section{How can current and future prevention programmes be improved?}

The low baseline drug literacy scores in the current study shine a light on key areas of focus for older adolescent AOD programme. Developing normative expectations continues to be a challenge in AOD prevention, and misconceptions around peer prevalence use were barely corrected by the current programme. ${ }^{58}$ Programme should seek creative ways to alleviate the cognitive dissonance occurring in certain youth groups. Additionally, while in the current study students demonstrated high confidence knowing where to seek help when experiencing general psychological distress, the low level of actual help-seeking behaviours documented in young people $^{52}$ indicates that the greater challenge lies in finding the motivation to know when to seek help. Hereby, the programme could focus on building motivation and setting positive health goals to empower young people to engage in the health system early. For older adolescents, it appears advantageous to provide less content but focus on relevant skill development. ${ }^{20}$ Finally, broadening the scope of harm-minimisation programme to include common addictive behaviours outside substance use may help to further destigmatise unhealthy behaviours and encourage the development of sophisticated life skills. These points will be addressed before a large-scale trial of the programme is conducted. Finally, programme facilitated by the internet could provide added implementation ease and could be effective in engaging time poor, senior students transitioning out of school.

\section{LIMITATIONS}

The drug literacy results presented in this pilot study are preliminary and should be interpreted with caution. The limited range of schools, variation in class size and age of students restrict the generalisability of results. In addition, the study did not contain a control group and there is no long-term follow-up to assess ongoing impact; therefore, a larger effectiveness trial is needed to determine intervention effects on literacy and student AOD use. The measures did not report actual drug use outcomes, instead intentions to use and perceived skills, attitudes and knowledge were examined; nevertheless, research shows that intentions are highly predictive of actual use. ${ }^{59}$ Some students $(n=16)$ did not include identifying data on their questionnaire, preventing their preprogramme and postprogramme questionnaires from being linked and included in the study, which contributes to the inconclusive results around the programme's impact on drug literacy levels. Future school-based research should employ other methods to link data while maintaining confidentiality. Measures of implementation delivery were not collected, nor were the number of workshops attended by each participant noted. A large-scale randomised controlled trial will be able to address these limitations.

\section{CONCLUSION}

In conclusion, this study provides preliminary evidence that delivering neuroscience-based education could be suitable to engage both high-risk and low-risk people in 
harm-minimisation prevention strategies. The current programme, The Illicit Project, appears feasible in the stage 5 (aged 15-16 years) and stage 6 (aged 16-19 years) NSW school system and is supported by teachers and health professionals. Next, a large-scale randomised controlled trial of the programme will be conducted to gain further insight into the potential of neuroscience to increase drug literacy and reduce AOD harms. Ultimately, to improve the lives of the next generation of young people, innovative new models must be explored.

\section{Twitter Jennifer Debenham @jennidebenham}

Acknowledgements The authors would like to acknowledge Mina Askovic, Chris Eassey and Jennifer Debenham for their work in delivering multiple workshops to schools. We are also extremely grateful to the schools, students, teachers and health professionals who participated in this research.

Contributors JD, NN and LB designed the study and gained ethical approval to conduct the study in schools. MA helped with data collection and KC assisted with the final write-up and review of the article. All authors contributed to the writing of the manuscript.

Funding The authors have not declared a specific grant for this research from any funding agency in the public, commercial or not-for-profit sectors.

Competing interests JD and MA are two of the developers of The Illicit Project programme.

Patient consent for publication Not required.

Ethics approval All aspects of the study were approved by UNSW Human Ethics committee (HC 180316), the University of Sydney Human Ethics committee (2018/887) and State Education Research Applications Process (SERAP) Ethics board (2018320).

Provenance and peer review Not commissioned; externally peer reviewed.

Data availability statement № additional data are available.

Open access This is an open access article distributed in accordance with the Creative Commons Attribution Non Commercial (CC BY-NC 4.0) license, which permits others to distribute, remix, adapt, build upon this work non-commercially, and license their derivative works on different terms, provided the original work is properly cited, appropriate credit is given, any changes made indicated, and the use is non-commercial. See: http://creativecommons.org/licenses/by-nc/4.0/.

\section{ORCID iDs}

Jennifer Debenham http://orcid.org/0000-0002-9596-9484

Katrina Champion http://orcid.org/0000-0001-8319-9366

\section{REFERENCES}

1 Degenhardt L, Charlson F, Ferrari A, et al. The global burden of disease attributable to alcohol and drug use in 195 countries and territories, 1990-2016: a systematic analysis for the global burden of disease study 2016. Lancet Psychiatry 2018;5:987-1012.

2 Gore FM, Bloem PJN, Patton GC, et al. Global burden of disease in young people aged 10-24 years: a systematic analysis. The Lancet 2011;377:2093-102.

3 Johnston LD, Miech RA, O'Malley PM, et al. Monitoring the future national survey results on drug use, 1975-2018: overview, key findings on adolescent drug use. Ann Arbor: Institute for Socia Research, The University of Michigan, 2019.

4 EMCfDaD A. Results from the European school survey project on alcohol and other drugs. Lisbon: Publications Office of the European Union, 2016

5 Welfare AloHa. National drug strategy household survey 2016: detailed findings. drug statistics series no 31. Canberra: AlHW, 2016.

6 Hibell B, Guttormsson U, Ahlstrom S, et al. The 2011 ESPAD report: substance use among students in 36 European countries. Stockholm, Sweden: The Swedish Council for Information on Alcohol and Other Drugs, 2012

7 Australian Institute of Health and Welfare. National drug strategy household survey (NDSHS) 2016 key findings. Canberra: AlHW, 2017.

8 Teesson M, Newton NC, Barrett EL. Australian school-based prevention programs for alcohol and other drugs: a systematic review. Drug Alcohol Rev 2012;31:731-6.
9 Emmers E, Bekkering GE, Hannes K. Prevention of alcohol and drug misuse in adolescents: an overview of systematic reviews. Nordic Studies on Alcohol and Drugs 2015;32:183-98.

10 Agabio R, Trincas G, Floris F, et al. A systematic review of schoolbased alcohol and other drug prevention programs. $\mathrm{CPEMH}$ 2015;11:102-12.

11 Faggiano F, Vigna-Taglianti FD, Versino E, et al. School-Based prevention for illicit drugs use: a systematic review. Prev Med 2008;46:385-96.

12 Newton NC, Conrod PJ, Slade T, et al. The long-term effectiveness of a selective, personality-targeted prevention program in reducing alcohol use and related harms: a cluster randomized controlled trial. J Child Psychol Psychiatry 2016;57:1056-65.

13 Lee NK, Cameron J, Battams S, et al. What works in schoolbased alcohol education: a systematic review. Health Educ $J$ 2016;75:780-98.

14 Australian Curriculum Assessment and Reporting Authority. Foundation to year 10 Australian curriculum (v8.3): health and physical education, 2016. Available: http://www. australiancurriculum.edu.au/health-and-physical-education/ curriculum

15 Foxcroft DR, Tsertsvadze A. Universal multi-component prevention programs for alcohol misuse in young people. Cochrane Database Syst Rev 2011;73.

16 McBride N, Farringdon F, Midford R, et al. Harm minimization in school drug education: final results of the school health and alcohol harm reduction project (SHAHRP). Addiction 2004;99:278-91.

17 Midford R, Munro G, McBride N, et al. Principles that underpin effective school-based drug education. J Drug Educ 2002;32:363-86.

18 Guzys D, Kendall S. Advocating for a harm-minimization approach to drug education in Australian schools. J Sch Nurs 2006;22:259-63.

19 Cahill HW. Challenges in adopting evidence-based school drug education programmes. Oxford, UK: Blackwell Publishing Ltd, 2007: 673-9.

20 Cuijpers P. Effective ingredients of school-based drug prevention programs. A systematic review. Addict Behav 2002;27:1009-23.

21 Gorman D. Does the life skills training program reduce use of marijuana? Addict Res Theory 2011;19:470-81.

22 Spaeth M, Weichold K, Silbereisen RK, et al. Examining the differential effectiveness of a life skills program (IPSY) on alcohol use trajectories in early adolescence. J Consult Clin Psychol 2010;78:334-48.

23 Caria MP, Faggiano F, Bellocco R, et al. The influence of socioeconomic environment on the effectiveness of alcohol prevention among European students: a cluster randomized controlled trial. BMC Public Health 2011;11:312.

24 Tobler NS, Stratton HH. Effectiveness of school-based drug prevention programs: a meta-analysis of the research. J Prim Prev 1997;18:71-128.

25 Kari Lancaster AR. Francis Metthew-Simmons Young people's opinions on alcohol and other drugs issues. National Drug and Alcohol Research Centre (Australia): National Drug and Alcohol Research Centre, University of New South Wales, 2013.

26 Abuse S. Chapter 4, early intervention, treatment and management of substance use disorders. Washington DC: Substance Abuse and Mental Health Services Administration (US), 2016.

27 Nation M, Crusto C, Wandersman A, et al. What works in prevention: principles of effective prevention programs. American Psychologist 2003:58:449-56.

28 Murthy VH. Facing Addiction in the United States: The Surgeon General's Report of Alcohol, Drugs, and Health. JAMA 2017;317:133-4

29 Lize SE, lachini AL, Tang W, et al. A meta-analysis of the effectiveness of interactive middle school cannabis prevention programs. Prev Sci 2017;18:50-60.

30 Baker DA, Ware JM, Schweitzer NJ, et al. Making sense of research on the Neurolmage bias. Public Understanding of Science 2017;26:251-8

31 Greene E, Cahill BS. Effects of neuroimaging evidence on mock Juror decision making. Behav Sci Law 2012;30:280-96.

32 Weisberg DS, Keil FC, Goodstein J, et al. The Seductive Allure of neuroscience explanations. J Cogn Neurosci 2008;20:470-7.

33 Weisberg D, Taylor J, Hopkins E. Deconstructing the seductive allure of neuroscience explanations. J Behav Decis Making 2015;10:429-41.

34 McCabe DP, Castel AD. Seeing is believing: the effect of brain images on judgments of scientific Reasoning. Cognition 2008;107:343-52.

35 Beck DM. The appeal of the brain in the popular press. Perspect Psychol Sci 2010;5:762-6. 
36 Fox CM. Brain awareness day: a Service-Learning experience in neuroscience. J Coll Sci Teach 2007;37:40-5.

37 Zardetto-Smith AM, Mu K, Carruth LL, et al. Brains rule!: a model program for developing professional stewardship among neuroscientists. CBE Life Sci Educ 2006;5:158-66.

38 Sperduti A, Crivellaro F, Rossi PF, et al. "Do Octopuses Have a Brain?" Knowledge, Perceptions and Attitudes towards Neuroscience at School. PLoS One 2012;7:e47943.

39 Ekhtiari H, Rezapour T, Aupperle RL, et al. Neuroscience-informed psychoeducation for addiction medicine: a neurocognitive perspective. Prog Brain Res 2017;235:239-64.

40 Kim-Spoon J, Kahn RE, Lauharatanahirun N, et al. Executive functioning and substance use in adolescence: neurobiological and behavioral perspectives. Neuropsychologia 2017;100:79-92.

41 Debenham J, Newton N, Birrell L, et al. Alcohol and other drug prevention for older adolescents: it's a no brainer. Drug Alcohol Rev 2019;38:327-30.

42 Newton NC, Teesson M, Vogl LE, et al. Internet-Based prevention for alcohol and cannabis use: final results of the climate schools course. Addiction 2010;105:749-59.

43 Newton NC, Conrod PJ, Rodriguez DM, et al. A pilot study of an online universal school-based intervention to prevent alcohol and cannabis use in the UK. BMJ Open 2014;4:e004750.

44 Newton NC, Teesson M, Barrett EL, et al. The cap study, evaluation of integrated universal and selective prevention strategies for youth alcohol misuse: study protocol of a cluster randomized controlled trial. BMC Psychiatry 2012;12:118.

45 NCETA. Peer education: from evidence to practice. Adelaide: National Centre for Education and Training on Addiction Flinders University of South Australia: National Centre for Education and National Centre for Education and Training on Addiction Training on Addiction, 2003

46 Degenhardt L, Stockings E, Patton G, et al. The increasing global health priority of substance use in young people. Lancet Psychiatry 2016;3:251-64.

47 DuPont RL, Han B, Shea CL, et al. Drug use among youth: national survey data support a common liability of all drug use. Prev Med 2018;113:68-73.
48 Mewton L, Visontay R, Chapman C. Universal prevention of alcohol and drug use: an overview of reviews in an Australian context. Melbourne: John Wiley \& Sons Australia, Ltd, 2018: S435-69.

49 Salaheddin K, Mason B. Identifying barriers to mental health helpseeking among young adults in the UK: a cross-sectional survey. $\mathrm{Br}$ J Gen Pract 2016;66:e686-92.

50 Loughman A, Haslam N. Neuroscientific explanations and the stigma of mental disorder: a meta-analytic study. Cogn Res Princ Implic 2018;3:43.

51 Livingston JD, Milne T, Fang ML, et al. The effectiveness of interventions for reducing stigma related to substance use disorders: a systematic review. Addiction 2012;107:39-50.

52 Gulliver A, Griffiths KM, Christensen H. Perceived barriers and facilitators to mental health help-seeking in young people: a systematic review. BMC Psychiatry 2010;10:113.

53 Cheng Meng-Tzu, Annetta L, Folta E, et al. Drugs and the brain: learning the impact of methamphetamine abuse on the brain through a virtual brain exhibit in the museum. Int J Sci Educ 2011;33:299-319.

54 Tang Y-Y. The neuroscience of mindfulness meditation how the body and mind work together to change our behaviour. Cham: Springer International Publishing, 2017.

55 Moreines J, Florance J, Glance J, et al. 1021. Bringing Neuroscience to the Clinic: Patients' Perceived Value of Trainee-Delivered Neuroscience Content in an Intensive Outpatient Program for Substance Use Disorders. Biol Psychiatry 2017;81:S412-3.

56 Frydenberg E. In: Raton B, ed. Adolescent coping: promoting resilience and well-being. 3rd edn. Boca Raton, FL: Routledge, an imprint of Taylor and Francis, 2018.

57 Monshat K, Khong B, Hassed C, et al. "A conscious control over life and my emotions:" mindfulness practice and healthy young people. A qualitative study. J Adolesc Health 2013;52:572-7.

58 Gewin AM, Hoffman B. Introducing the cultural variables in school-based substance abuse prevention. Drugs Educ Prev Polic 2016;23:1-14.

59 Maddahian E, Newcomb MD, Bentler PM. Adolescent drug use and intention to use drugs: concurrent and longitudinal analyses of four ethnic groups. Addict Behav 1988;13:191-5 